\title{
Comparison of empirical correlations for the oxygen transfer coefficient estimation in an aerobic bioprocess
}

\author{
Maribel Ruiz-Botero \\ Grupo de Automática, \\ Electrónica y Ciencias \\ Computacionales, Grupo de \\ Calidad, Metrología y \\ Producción \\ Instituto Tecnológico \\ Metropolitano \\ maribelruiz@itm.edu.co
}

\author{
Christian Zuluaga- \\ Bedoya \\ Grupo de Calidad, \\ Metrología y Producción, \\ Instituto Tecnológico \\ Metropolitano \\ zuluagabedoya@gmail.com
}

\author{
Manuel Ospina-Alarcon \\ Grupo de Automática, \\ Electrónica y Ciencias \\ Computacionales, \\ Instituto Tecnológico \\ Metropolitano \\ manuelospina@itm.edu.co
}

\author{
Jose Garcia-Tirado \\ Grupo de Calidad, \\ Metrología y Producción, \\ Instituto Tecnológico \\ Metropolitano \\ josegarcia@itm.edu.co
}

(Paper type: Scientific and Technological Research. Received 10/08/2016. Probed 22/09/2016)

Abstract. This paper shows a comparison of three different empirical correlations found in the literature for the estimation of the oxygen transfer coefficient in an aeration pilot plant using a phenomenological-based semi-physical model (PBSM). The relationship between each empirical correlation and the oxygen transfer phenomenon from the gas phase to the liquid phase was assessed. The results showed that empirical correlations of the oxygen transfer coefficient found in the literature are not based on the knowledge of the physical phenomena, and hence are not suitable to generalize the transference mechanism in similar processes.

Keywords. Aeration, Bioprocess, Estimation, Mass transfer coefficient, Oxygen scavenger

\section{Comparación de correlaciones empíricas para la estimación del coeficiente de transferencia de oxígeno en bioprocesos aeróbicos}

\begin{abstract}
Resumen. Este artículo muestra una comparación de tres correlaciones empíricas encontradas en la literatura para la estimación del coeficiente de transferencia de oxígeno en una planta piloto de aireación. Para este fin, se usa un modelo semifísico de base fenomenológica (MSBF) de una planta piloto disponible. Con esta evaluación, se puso a prueba la relación entre las correlaciones empíricas y el fenómeno de transferencia de oxígeno desde la fase gaseosa a la fase líquida. Los resultados muestran que las correlaciones empíricas encontradas en la literatura para determinar el coeficiente de transferencia de oxígeno, no son basadas en el conocimiento del fenómeno físico y por lo tanto no son adecuadas para generalizar el mecanismo de transferencia en otros procesos similares.
\end{abstract}

Palabras clave. Aireación, Bioproceso, Estimación, Coeficiente de transferencia de masa, Secuestrante de oxígeno

\section{Introduction}

Aeration is the process of air circulation through a liquid or substance for mixing or dissolution. This operation of mass transfer has a high importance at the industry level as well as in the operation of different public services. Some applications where aeration is required are volatile substances removal in liquid streams, subaquatic species culturing for food (industrial aquaculture), wastewater treatment, and recombinant proteins design to diverse applications of biological processes where high amounts of enzymes, food and biomedical and pharmaceutical products processing.

Dissolved oxygen (DO) concentration control is a critical operation for guaranteeing the growth of a diverse group of micro-organisms and multicellular organisms in different bioprocesses. Process variables like temperature, $\mathrm{pH}$, biomass concentration, amount of foam, among others, affect nonlinearly the DO concentration and hence difficult its control. Typically, the oxygenation of microorganisms is performed by aerators, which are basically bioreactors with an ascendant air flow (or pure oxygen) from the tank bottom. Applications of processes and bioprocesses using aerators are found in [1], [2] and [3].

In the case of biological wastewater treatment, there are some aspects hampering the DO control. First, mass transfer of oxygen from gas to liquid phase is considered an activity of high energy consumption [1]. Regarding to the regulation of $\mathrm{OD}$ concentration, a precise tracking of the operation trajectories must be performed in order to avoid cell death due to oxygen absence or cell stress inhibition by oxygen excess. Sometimes, this phenomenon does not occur, but this operation may represent cost overruns.

In processes where a metabolite is obtained from cell growth, also death and inhibition phenomena are present due to absence or excess of oxygen, respectively. Moreover, production of secondary products (nondesirable products) have been reported, owing to limitations in oxygen mass transfer [4].

It is important to highlight that the mass transfer models presented in the literature used empirical correlations to determine the values of some process sensitive parameters, e.g., the mass transfer coefficient $\left(k_{L} a\right)$, the interfacial area $(a)$, the bubble diameter, among others, regarding only to aerated tanks. These correlations typically assume a specific operation regime and conditions of each process without the consideration of the phenomena taking place. Therefore, generalization to different scenarios and operating points or similar aerobic processes is not possible. 
In this paper, three empirical correlations for estimating the oxygen transference coefficient for aerators are tested in a phenomenological-based semiphysical model (PBSM) of a pilot plant in order to assess its impact on the dynamical evolution of the process. The PSBM is a grey-box model with first principles equations and some parameters found from data [5].

The paper is organized as follows. In Section 2, a substance that emulates the role of microorganisms (oxygen scavenger) is presented together with a phenomenological-based semi-physical model of the pilot plant under interest. Later, the empirical correlations are presented and tested in the PSBM in order to assess its impact on the dynamical evolution of the process in Section 3. Finally, concluding remarks are presented in Section 4.

\section{Materials and methods}

In order to emulate the operation of the aerobic stage of a biological wastewater plant in a non-biological environment, the biomass is replaced by a chemical oxygen scavenger. Then, the oxygen scavenger is dynamics is added to a PBSM. Finally, the empirical correlations reviewed from literature are presented.

\subsection{Oxygen scavenger}

A substance able to remove the dissolved oxygen from the water or aqueous systems is usually known as oxygen scavenger. Typically, oxygen scavengers are used to prevent oxidative reactions on metals and other substances in the industry and science. For example, in oil industry, the oxygen scavengers are used to avoid corrosion in metal pipelines and process equipment [6]. In the food industry, the oxygen scavengers are packed and put in the food storage spaces, contributing to food preservation. Regarding to the chemical industry, oxygen scavengers are added to boilers, furnaces and service fluid systems. The most common oxygen scavengers found are:

- Bisulfite, metabisulfite, sulfite salts.

- Hydrazines

- Hydroxylamines

- Activated aldehydes

- Polyhydroxyl compounds

Alternatively, DO can be removed by thermal or biological treatment. Thermal treatment is based on raising temperature and pressure, taking advantage of the property of solubility in order to volatilize dissolved gases, not only oxygen. However, this treatment is only applicable in the chemical process industry using deaerators. Biological treatment is based on the use of microorganisms, which partially consume the dissolved oxygen through their respiration processes.

Several works are found in literature about the role of oxygen scavengers emulating bacterial respiration [7], [8] [9], [10]. However, most of these contributions are focused on catalyzed reactions. In [7], an aqueous solution of sodium sulfite is used for uncatalyzed oxidation as a mechanism for simulation of bacterial respiration. The sulfite exhibited a zero-order kinetics with respect to the sulfite concentration and order 0.65 with respect to dissolved oxygen concentration. This result is studied in both well-agitated reactors and quiescent pools of sulfite solutions. Similarly, in [8] the kinetics of three oxygen scavengers reactions: sodium sulfite, sodium bisulfite, and sodium pyrosulfite is compared. The authors found that all scavengers approximately have the same zero-order reaction coefficient. Moreover, these kinetic coefficients depend on the buffer concentration, i.e., they are dependent of the solution $\mathrm{pH}$.

In this contribution, the emulation of the oxygen consumption of a biological wastewater treatment is made by a chemical oxygen scavenger. The kinetic expressions are taken from [7], [8] to model sodium sulfite consumption and its effect on dissolved oxygen concentration. Then, the kinetics of oxygen scavenger is incorporated to the DO dynamic equation, which gives an estimate of equilibrium between oxygen mass transfer from the air and consumption due to the scavenger.

\subsection{A mathematical model of an aeration pilot plant}

Consider a pilot plant as in the pipe and instrumentation diagram (P\&ID) in Figure 1. In this process, an aqueous solution is fed to the process tank to perform a transfer mass activity. This stream is preheated to $30^{\circ} \mathrm{C}$ in an external heat exchanger. In addition, an air stream is connected from a compressor to an air sparger inside the reactor, distributing bubbles in the reaction medium.

Once in the tank, liquid and bubbles are in contact, with the objective to promote oxygen transfer from the gas phase to the liquid phase. This mass transfer operation is affected by different parameters such as operational conditions and hydrodynamic effects taking place in the process. This influence is represented by a global mass transfer coefficient, which is included in the mass balances. In order to emulate the oxygen consumption from microorganisms, an oxygen scavenger is added to the reactor before the process start-up. This chemical compound will consume part of transferred oxygen from air bubbles to the liquid.

Material and energy balances are formulated under the different process systems in the reactor. A complete methodology for development of PBSM's is found in [5]. Equation (1) describes the total material balance of the system, (2) - (3) are energy balances in the tank and the inlet stream, (4) is the dissolved oxygen material balance in the reactor, and (5) is the oxygen scavenger molar balance in the reactor. 


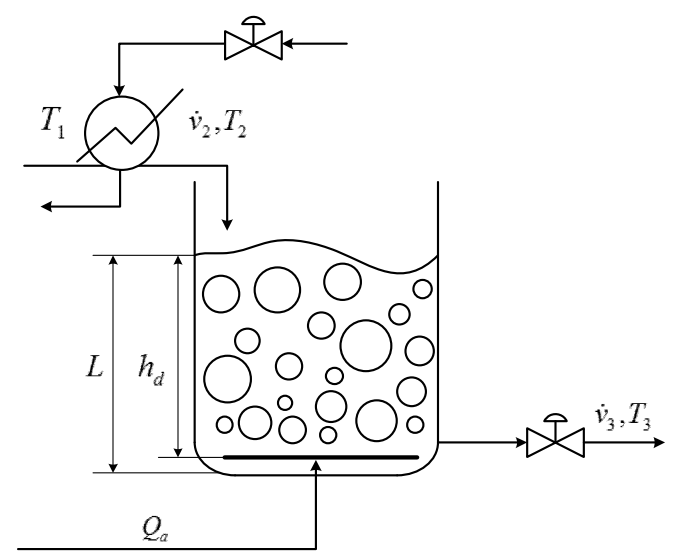

Figure 1. Process flow diagram of aerated reactor.

$\frac{d L}{d t}=\frac{1}{A_{c s}}\left(\dot{v}_{2}-\dot{v}_{3}\right)$

$\frac{d T_{3}}{d t}=\frac{1}{A_{c s} L}\left(\dot{v}_{2} T_{2}-\dot{v}_{3} T_{3}\right)-\frac{T_{3}}{L} \frac{d L}{d t}$

$\frac{d T_{2}}{d t}=\frac{\dot{v}_{2}}{V_{h e}}\left(T_{1}-T_{2}\right)+\frac{Q}{\rho V_{h e} C_{p}}$

$\frac{d C_{O, 3}}{d t}=\frac{1}{V_{L}}\left(\dot{v}_{2} C_{O, 2}-\dot{v}_{3} C_{O, 3}\right)+k_{L} a\left(C_{O}^{*}-C_{O, 3}\right)-\ldots$

$\ldots-M_{O D} k_{O S} C_{O S, 3}^{0.65}$

$\frac{d C_{O S, 3}}{d t}=\frac{1}{V_{L}}\left(\frac{\dot{m}_{O S}}{M_{O S}}-\dot{v}_{3} C_{O S, 3}\right)-k_{S}$

$\dot{v}_{3}=C_{v} \sqrt{L}$

$A_{c s}=\pi D_{t}^{2} / 4$

$Q=U A_{h e}\left(600-T_{1}\right)$

$V_{L}=0.7 A_{c s} L$

Where $L[m]$ is the reactor level, $T_{3}[K]$ is the reactor temperature, $T_{2}[K]$ is the temperature in the inlet stream to the reactor, $C_{O, 3}\left[\mathrm{~kg} / \mathrm{m}^{3}\right]$ is the dissolved oxygen concentration in the reactor, and $C_{O S, 3}\left[\mathrm{~mol} / \mathrm{m}^{3}\right.$ ] is the oxygen scavenger concentration in the reactor. The input variables are the inlet air volumetric flow rate ( $\left.Q_{a}\right)\left[\mathrm{m}^{3} / \mathrm{s}\right]$ and the oxygen scavenger mass flow rate added to the reactor $\left(\dot{m}_{O S}\right)[\mathrm{kg} / \mathrm{s}]$. The parameters in (1) - (9) are presented in the Table 1.
Ingenierías USBMed, Volumen 7, No. 2, Julio-Diciembre 2016

Table 1. Parameters of the process model (1/2)

\begin{tabular}{|c|c|c|}
\hline Parameter & Description & Value \\
\hline$A_{c s}$ & $\begin{array}{l}\text { Reactor cross sectional } \\
\text { area }\end{array}$ & - \\
\hline$D_{t}$ & Reactor diameter & $0.4 m$ \\
\hline$\dot{v}_{2}$ & $\begin{array}{l}\text { Inlet liquid volumetric flow } \\
\text { rate to the reactor. }\end{array}$ & $0.00025 \frac{m^{3}}{s}$ \\
\hline$\dot{v}_{3}$ & $\begin{array}{l}\text { Outlet liquid volumetric } \\
\text { flow rate from the reactor }\end{array}$ & - \\
\hline$C_{v}$ & $\begin{array}{l}\text { Flow coefficient of the } \\
\text { valve in the outlet stream }\end{array}$ & $4.5644 \times 10^{-4} \frac{m^{3}}{s \sqrt{m}}$ \\
\hline$V_{h e}$ & Heat exchanger volume & $0.0051 \mathrm{~m}^{3}$ \\
\hline$T_{1}$ & $\begin{array}{l}\text { Temperature of inlet liquid } \\
\text { stream to the heat } \\
\text { exchanger }\end{array}$ & $298.15 K$ \\
\hline$Q$ & Heat transfer rate & - \\
\hline$U$ & $\begin{array}{l}\text { Global heat transfer } \\
\text { coefficient }\end{array}$ & $682.1451 \frac{W}{m^{2} K}$ \\
\hline$A_{h e}$ & Heat transfer area & $0.0254 m^{2}$ \\
\hline$\rho$ & $\begin{array}{l}\text { Inlet liquid density to the } \\
\text { reactor }\end{array}$ & $1000 \frac{\mathrm{kg}}{\mathrm{m}^{3}}$ \\
\hline$C_{p}$ & $\begin{array}{l}\text { Inlet liquid heat capacity to } \\
\text { the reactor }\end{array}$ & $4184 \frac{J}{k g K}$ \\
\hline$V_{L}$ & $\begin{array}{l}\text { Liquid volume in the } \\
\text { reactor }\end{array}$ & - \\
\hline$C_{O, 2}$ & $\begin{array}{l}\text { Dissolved oxygen } \\
\text { concentration in the inlet } \\
\text { liquid stream }\end{array}$ & $0.005138 \frac{\mathrm{kg}}{\mathrm{m}^{3}}$ \\
\hline$k_{L} a$ & Mass transfer coefficient & - \\
\hline$C_{O}^{*}$ & $\begin{array}{l}\text { Equilibrium dissolved } \\
\text { oxygen concentration in } \\
\text { the liquid }\end{array}$ & $0.00734 \frac{\mathrm{kg}}{\mathrm{m}^{3}}$ \\
\hline
\end{tabular}

Table 2. Parameters of the process model (2/2)

\begin{tabular}{lll}
\hline$k_{O S}$ & $\begin{array}{l}\text { Dissolved } \\
\text { consumption rate }\end{array}$ oxygen & $5.77 \times 10^{-5} \frac{M^{0.35}}{s}$ \\
\hline$k_{S}$ & $\begin{array}{l}\text { Oxygen scavenger } \\
\text { consumption rate }\end{array}$ & $3.7222 \times 10^{-7} \frac{M^{*}}{s}$ \\
\hline$M_{O S}$ & $\begin{array}{l}\text { Oxygen scavenger molar } \\
\text { mass }\end{array}$ & $126.043 \frac{\mathrm{gol}}{\mathrm{mol}}$ \\
\hline$M_{O D}$ & $\begin{array}{l}\text { Dissolved oxygen molar } \\
\text { mass }\end{array}$ & $32 \frac{\mathrm{g}}{\mathrm{mol}}$ \\
\hline
\end{tabular}

${ }^{*}$ Molarity unit

\subsection{Mass transfer coefficient}

The three empirical correlation to estimate the oxygen transfer coefficient were proposed by different authors between 2006 and 2014 in [11], [12] and [13], respectively. The main feature to note about these 
correlations is that are written in terms of the reactor geometric parameters, allowing an easier comparison from each other.

In order to perform the estimation of the oxygen transfer coefficient using the three reviewed correlations, the dimensionless Reynolds and Froude numbers are computed by means of (10) and (11) using the parameters listed in Table 3.

$$
\begin{aligned}
& R e=\frac{Q_{a} \rho}{D_{t} \mu} \\
& F r=\frac{Q_{a}}{\sqrt{D_{t}^{5} g}}
\end{aligned}
$$

Table 3. Parameters of oxygen transfer coefficient correlations

\begin{tabular}{clc}
\hline Parameter & \multicolumn{1}{c}{ Description } & Value \\
\hline$\mu$ & Liquid dynamic viscosity & $9.8 \times 10^{-4} \frac{\mathrm{kg}}{\mathrm{ms}}$ \\
\hline$g$ & Gravity & $9.81 \frac{\mathrm{m}}{\mathrm{s}^{2}}$ \\
\hline$v$ & Liquid kinematic viscosity & $0.8 \times 10^{-6} \frac{\mathrm{m}^{2}}{\mathrm{~s}}$ \\
\hline$D$ & $\begin{array}{l}\text { Diffusion coefficient of air in } \\
\text { water }\end{array}$ & $1.86 \times 10^{-9} \frac{\mathrm{m}^{2}}{\mathrm{~s}}$ \\
\hline$h_{d}$ & Depth to diffuser & - \\
\hline$d_{b}$ & Bubble diameter & $0.005 \mathrm{~m}^{-}$ \\
\hline$H_{t}$ & Reactor height & - \\
\hline$A_{d}$ & Surface area of the diffusers & $0.0491 \mathrm{~m}^{2}$ \\
\hline
\end{tabular}

The values $h_{d}$ and $H_{t}$ are function of $L$ at each time step.

\subsubsection{Schierholz et al. [11] correlation}

In 2006, Schierholz et al. [11] presented two empirical correlations to determine the oxygen transfer coefficient from a gas to liquid phase. The first correlation is for the system formed by the water surface in contact with fresh air and the second correlation is for the system formed by air bubbles from entering the reactor scattered through diffusers and the water within the reactor. $\ln (12)$ the authors presented the correlation proposed for the volumetric coefficient of mass transfer from the bubbles to the liquid and in (13) the correlation proposed from the air in contact with the liquid surface.

$$
\begin{aligned}
& k_{L} a_{b}=49 \operatorname{Re}\left(\frac{v}{D}\right)^{0.5}\left(\frac{D}{D_{t}^{2}}\right)\left(\frac{A_{t}}{h_{d}^{2}}\right)^{0.72} 2.484 \times 10^{6} \\
& \frac{k_{L} a_{s}}{Q_{a}}=49 \operatorname{Re}\left(\frac{v}{D}\right)^{0.5}\left(\frac{h_{d}^{2}}{A_{C S}}\right)^{0.28}
\end{aligned}
$$

\subsubsection{Al-Ahmady et al. [12] correlation}

Al-Ahmady et al. [12] in 2011 proposed an empirical correlation for determining the volumetric oxygen transfer coefficient from gas to liquid phase, based on the dimensionless Reynolds and Froude numbers, geometric relationships between the bubbles diameter and the depth to diffuser in the water, the reactor height and the reactor diameter, and the surface area of the diffusers and the reactor area.

$$
\frac{D_{t}^{2} k_{L} a}{D}=0.033 R e^{1.46} F r^{-0.49}\left(\frac{d_{b}}{h_{d}}\right)^{-0.73}\left(\frac{H_{t}}{D_{t}}\right)^{-1.77}\left(\frac{A_{d}}{A_{t}}\right)^{-0.24}
$$

\subsubsection{Pittoors et al. [13] correlation}

In 2014, Pittoors et al. [13] proposed empirical correlations to determine the volumetric oxygen transfer coefficient in clean water and activated sludge water. These correlations are given in terms of volume $\left(V_{t}\right)$, height $\left(H_{t}\right)$, diameter $\left(D_{t}\right)$ and cross-sectional area $\left(A_{t}\right)$ of the tank, air volumetric flow rate $\left(Q_{a}\right)$, superficial area $\left(A_{d}\right)$ and depth $\left(H_{d}\right)$ of the diffusers, bubble diameter $\left(d_{b}\right)$, and dynamic viscosity in a cylindrical reactor aerated by diffusion. The correlation for clean water is (15) and for water with activated sludge is (16) [13].

$$
\begin{aligned}
& k_{L} a_{C W}=\left(\frac{0.03 D}{D_{t}^{2}}\right) \operatorname{Re}^{1.718} \mathrm{Fr}^{-0.709}\left(\frac{d_{b}}{h_{d}}\right)^{-0.291}\left(\frac{H_{t}}{D_{t}}\right)^{-0.554} \\
& \left(\frac{A_{d}}{A_{t}}\right)^{0.135}\left(\frac{D_{t}}{h_{d}}\right)^{0.321}\left(\frac{H_{t}}{h_{d}}\right)^{0.086}\left(\frac{V_{t}}{A_{d}^{1.5}}\right)^{-0.017} \\
& k_{L} a_{A S}=\left(\frac{0.06 D}{D_{t}^{2}}\right) \operatorname{Re}^{1.906} \mathrm{Fr}^{-0.631}\left(\frac{d_{b}}{h_{d}}\right)^{-0.23}\left(\frac{H_{t}}{D_{t}}\right)^{-0.120} \\
& \left(\frac{A_{d}}{A_{t}}\right)^{0.326}\left(\frac{D_{t}}{h_{d}}\right)^{0.164}\left(\frac{H_{t}}{h_{d}}\right)^{0.173}\left(\frac{V_{t}}{A_{d}^{1.5}}\right)^{-0.01}
\end{aligned}
$$

\subsubsection{Reported mass transfer coefficient value}

A model for a biological wastewater treatment plant is presented in [14]. The model is a reduction of the ASM1 model, which was presented in 1987 by the International Water Association (IWA) [15]. The author used the following constant mass transfer coefficient in order to compare with different empirical correlation.

$$
k_{L} a=4.6296 \times 10^{-5} \frac{1}{s}
$$

\section{Results and Discussion}

The comparison methodology used in this work is based on the numerical value of the mass transfer coefficient and in the mathematical model solution obtained with the empiric correlations presented. The mathematical model was programmed and solved in the MATLAB® software version 2015b, using the ODE45 numerical method during $2000 \mathrm{~s}$.

The dynamic behavior of the mathematical model was evaluated under different inputs. The considered inputs 
were $1 \times 10^{-5} \mathrm{~m}^{3} / \mathrm{s}$ and $2 \times 10^{-5} \mathrm{~m}^{3} / \mathrm{s}$ in the inlet air volumetric flow rate $\left(Q_{a}\right)$ and $0.0001 \mathrm{~kg} / \mathrm{s}$ and $0.00005 \mathrm{~kg} / \mathrm{s}$ for the oxygen scavenger mass flow rate added to the reactor $\left(\dot{m}_{s c}\right)$, respectively. The change in the $\dot{m}_{s c}$ was performed at time $1000 s$ and the change in the $Q_{a}$ was performed at the time $1500 \mathrm{~s}$.
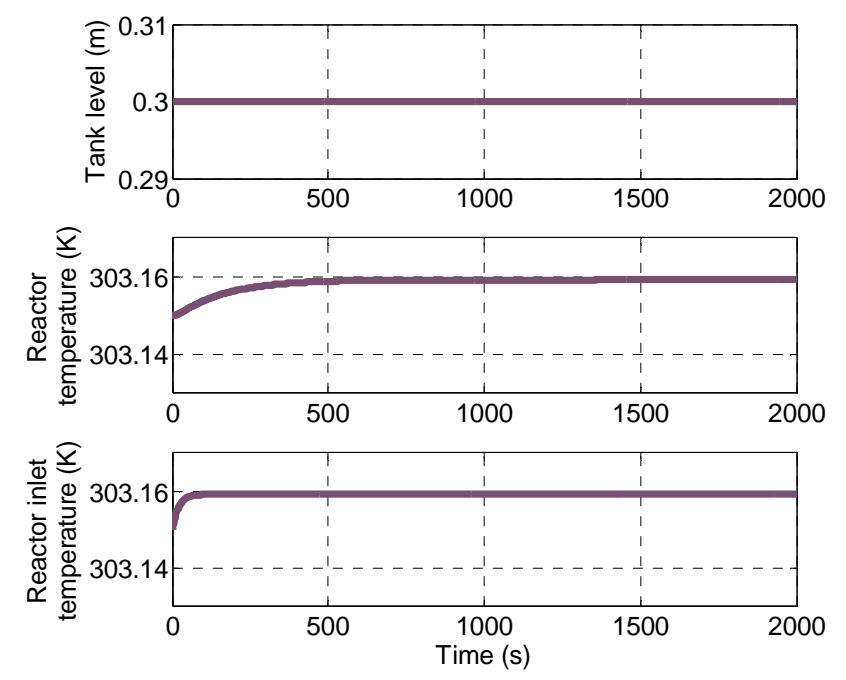

Figure 2. Dynamic response of tank level.

The proposed initial conditions were $0.3 \mathrm{~m}$ for level reactor, $303.15 \mathrm{~K}$ for the reactor temperature and the temperature in the inlet stream to the reactor, $0.00734 \mathrm{~kg} / \mathrm{m}^{3}$ for the dissolved oxygen concentration, and $0.0005 \mathrm{~kg} / \mathrm{m}^{3}$ for the oxygen scavenger concentration.

The reactor level dynamic equation does not depend on the concentration of dissolved oxygen in the system, and consequently the reactor level does not change for the different mass transfer coefficient estimates. In the same way, the temperature in the reactor and temperature in the inlet stream have a similar behavior for all simulations and stabilize both variables at the same value $303.1592 K$ (Figure 2).

Regarding to the oxygen scavenger, Figure 3 shows that initial accumulation of scavenger in the reactor is reached. In this time window, the DO concentration decays fast until a steady state is reached. After 1000 s, the mass flow rate is decreased and the oxygen decreased its rate of consumption, until next steady state is reached. In addition, the disturbance at $1500 \mathrm{~s}$ of the change in airflow, have a negligible effect on scavenger concentration, which confirms that scavenger consumption does not depend on dissolved oxygen concentration.

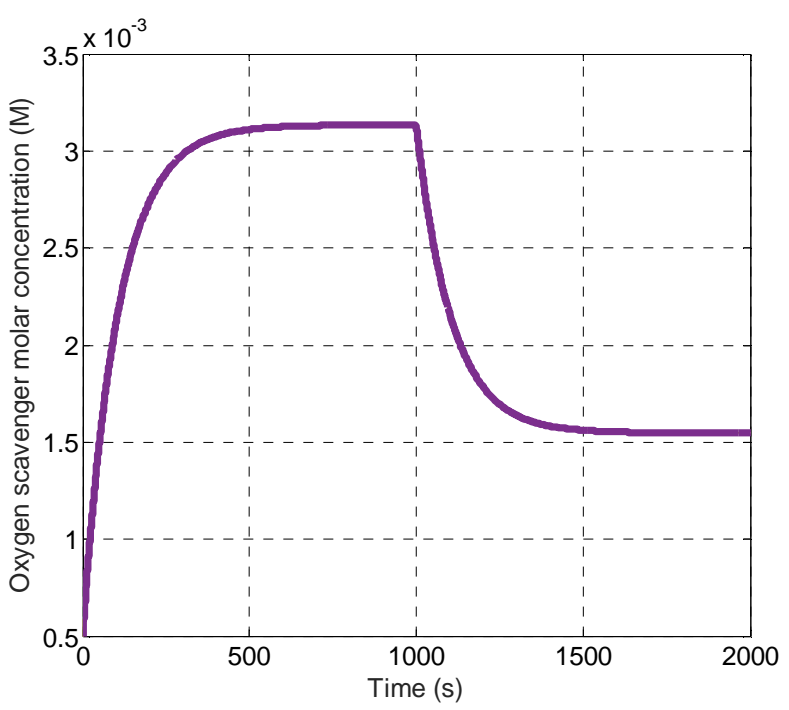

Figure 3. Dynamic response of oxygen scavenger.

On the other hand, since the oxygen transfer coefficient has a high impact on the DO concentration dynamics, the effect of the different correlations produces different dynamic evolutions as it is shown in Figure 4.

The different estimates computed by using the reviewed empirical correlations show the lack of consistency from each other. This fact might be explained since the different correlations are derived for very specific and narrow process conditions making difficult to find phenomenological connections among the correlations and hence hindering a possibility for generalization.

The different responses observed in Figure 2 show the lack of phenomenological knowledge about the mass transfer mechanism used in the empirical correlations. Therefore, any mathematical model using this type of correlations will deteriorate its prediction ability and hence will compromise every engineering task based on the mathematical model. In this sense, if the oxygen transfer coefficient is high it means that the oxygen transfer between the gas and the liquid phase is efficient and fast. In contrast, low values for the parameter show that mass transfer between phases is less efficient or there is a greater liquid resistance to the transference.

The model response with the value obtained for the mass transfer coefficient through the empirical correlation proposed by Al-Ahmady et al. [12], show that the system reaches the dissolved oxygen saturation concentration in water faster if compared with the values found by the remaining correlations, see Figure 4(b). This occurs due to the high numerical value of the mass transfer coefficient (Figure 5(a)), which makes the oxygen transfer from the gas to the liquid phase to stabilize faster to the saturation value. 


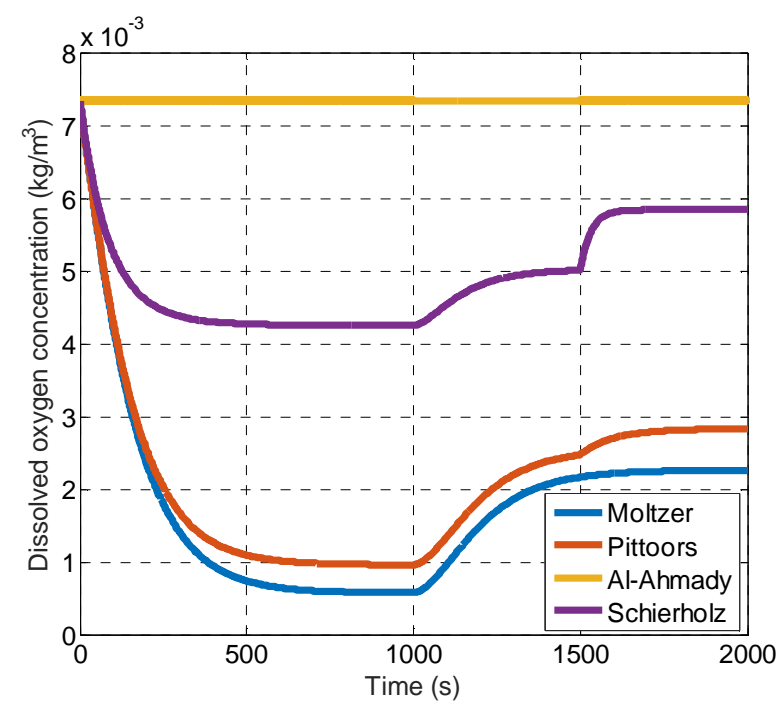

(a)

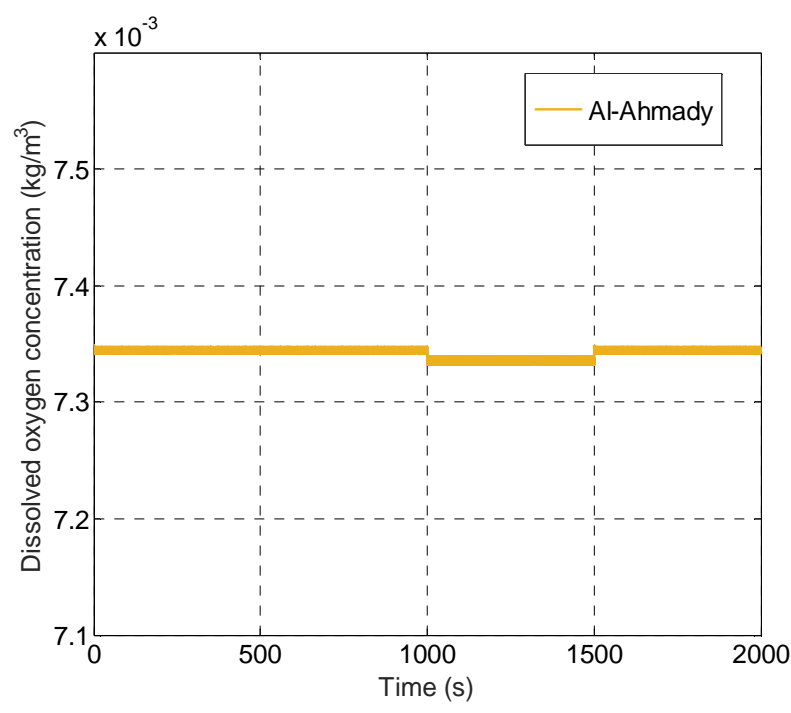

(b)

Figure 2. (a) Comparison of dissolved oxygen response. (b) Detailed view of dissolved oxygen dynamic with Al-Ahmady correlation

The values of the mass transfer coefficient obtained with the empirical correlation proposed by Schierholz et al. [11] are high compared with the constant value proposed in [14], but are low compared with the values obtained by the empirical correlation proposed by AlAhmady et al. [12].

The lowest value for the oxygen transfer coefficient obtained was determined with the correlation proposed by Pittoors et al. [13] (Figure 5(c)). However, the oxygen dissolved concentrations obtained with this empirical correlation are higher than those obtained with the constant value of the mass transfer coefficient proposed in [14].

As mentioned above, the empirical correlations evaluated have no physical genesis, as the values obtained showed different values for the same system under the same operating conditions. Then, it can be confirmed that the correlations presented by the authors were proposed under different operating conditions and therefore may not be applicable to every set of conditions.

Figure 5 present the numerical values obtained with each empirical correlation evaluated. The variation of these values at the time is due to the change in the input . As mentioned, the empirical correlation that yields the highest value for the mass transfer coefficient is proposed in [12] and the lowest value is presented in [13].

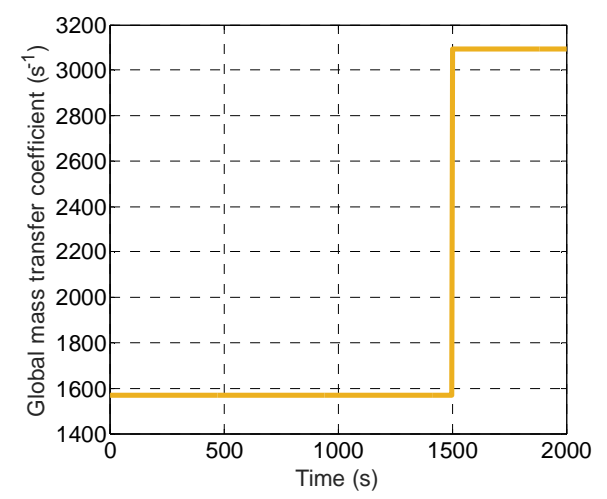

(a)

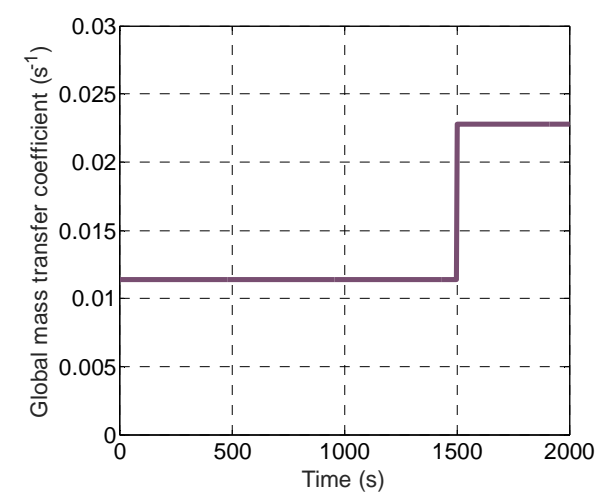

(b)

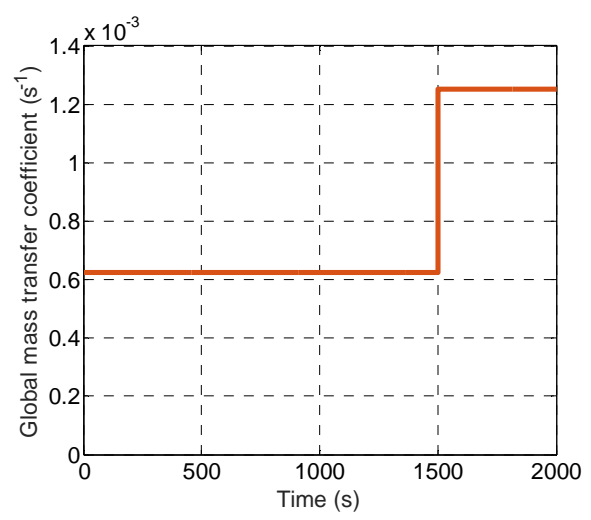

(c)

Figure 5. (a) Mass transfer coefficient from Al-Ahmady correlation. (b) Mass transfer coefficient from Schierholz correlation. (c) Mass transfer coefficient from Pittoors correlation.

\section{Conclusions}

Three empirical correlations for the oxygen transfer coefficient proposed by different authors have been evaluated in the numerical solution of a wastewater treatment plant model. This fact allowed to check that the knowledge on the mass transfer mechanism is still limited and hence the different available empirical 
correlations might not be adequate to describe many mass transfer processes. Process variables such reactor level and temperature have an indirect effect in the mass transfer process, the first one due to mass transfer area, which is directly related to reactor level. The reactor temperature in this case does not show an appreciable effect in oxygen transfer, but should be taken into account because it affects microorganism growth and with this, the oxygen concentration and mass transfer are affected as well.

The main contribution of this paper dealt with the comparison of different mass transfer coefficients found in the literature for oxygen transference. As it was shown, available expressions of mass transfer coefficients for oxygen transference have a tremendous empirical origin, despite of the use of dimensionless numbers. The results of this comparison presented differences of many orders of magnitude in the tested parameter, under the same operation conditions. Another contribution is achieved in the incorporation of the mass balance of the oxygen scavenger as a way to emulate the microorganism respiration.

\section{References}

[1] L. Åmand, "Control of aeration systems in activated sludge processes - a review," IVL Swedish Environ. Res. Institute/Department Inf. Technol. Uppsala Univ. Uppsala, Sweden, pp. 1-19, 2011.

[2] A. Amicarelli, F. Di Sciascio, J. M. Toibero, and H. Alvarez, "Including dissolved oxygen dynamics into the Bt $\delta$-Endotoxins Production process model and its application to process control," Brazilian J. Chem. Eng., vol. 27, no. 01, pp. 41-62, 2010.

[3] D. M. Atia, F. H. Fahmy, N. M. Ahmed, and H. T. Dorrah, "Design and Control Strategy of Diffused Air Aeration System," World Acad. Sci. Eng. Technol., vol. 6, no. 3, pp. 666-670, 2012.
[4] L. Åmand, G. Olsson, and B. Carlsson, "Aeration control - A review," Water Sci. Technol., vol. 67, pp. 2374-2398, 2013.

[5] H. Álvarez, R. Lamanna, P. Vega, and S. Revollar, "Metodología para la Obtención de Modelos Semifísicos de Base Fenomenológica Aplicada a una Sulfitadora de Jugo de Caña de Azúcar," Rev. Iberoam. Automática e Informática Ind. RIAI, vol. 6, no. 3, pp. 10-20, 2009.

[6] M. A. Kelland, Production Chemicals for the Oil and Gas Industry, Second Edition. CRC Press, 2014.

[7] P. Hui and H. Palmer, "Uncatalyzed oxidation of aqueous sodium sulfite and its ability to simulate bacterial respiration," Biotechnol. Bioeng., vol. 37, pp. 392-396, 1991.

[8] Y. Shi, X. Zhan, L. Ma, L. Li, and C. Li, "Evaluation of antioxidants using oxidation reaction rate constants," Front. Chem. China, vol. 2, no. 2, pp. 140-145, 2007.

[9] P. M. Wilkinson, B. Doldersum, P. H. M. R. Cramers, and L. L. Van Dierendonck, "The kinetics of uncatalyzed sodium sulfite oxidation," Chem. Eng. Sci., vol. 48, no. 5, pp. 933-941, 1993.

[10] R. Hermann, N. Walther, U. Maier, and J. Buchs, "Optical method for the determination of the oxygen-transfer capacity of small bioreactors based on sulfite oxidation," Biotechnol. Bioeng., vol. 74, no. 5, pp. 355-363, 2001.

[11] E. L. Schierholz, J. S. Gulliver, S. C. Wilhelms, and H. E. Henneman, "Gas transfer from air diffusers," Water Res., vol. 40, pp. 1018-1026, 2006.

[12] K. K. Al-Ahmady, "Mathematical Model for Calculating Oxygen Mass Transfer Coefficient in Diffused Air Systems," Al-Rafadain Eng. J., vol. 19, no. 4, pp. 43-54, 2011.

[13] E. Pittoors, Y. Guo, and S. W. H. Van Hulle, "Oxygen transfer model development based on activated sludge and clean water in diffused aerated cylindrical tanks," Chem. Eng. J., vol. 243, pp. 51-59, 2014.

[14] M. Moltzer, "Analysis of Robust Stability of Model Predictive Control for Biological Wastewater Treatment Plants," Eindhoven University of Technology, Eindhoven, Holanda, 2008.

[15] M. Henze, W. Gujer, T. Mino, and M. C. M. van Loosdrecht, "Activated Sludge Models ASM1, ASM2, ASM2d and ASM3," IWA Publ., p. 121, 2000 